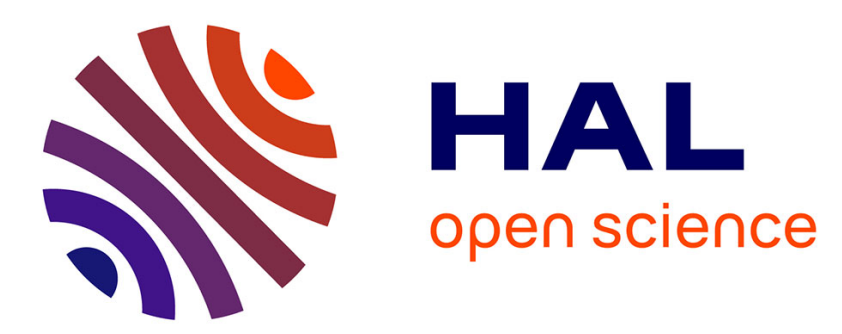

\title{
Growing imbedded Ni3C-rich layer with sharp interfaces by means of ion beam mixing of $\mathrm{C} / \mathrm{Ni}$ layers
}

Árpád Barna, László Kotis, János Lábár, Attila Sulyok, Attila L Tóth, Miklós Menyhárd, Peter Panjan

\section{- To cite this version:}

Árpád Barna, László Kotis, János Lábár, Attila Sulyok, Attila L Tóth, et al.. Growing imbedded Ni3C-rich layer with sharp interfaces by means of ion beam mixing of $\mathrm{C} / \mathrm{Ni}$ layers. Journal of Physics D: Applied Physics, 2011, 44 (12), pp.125405. 10.1088/0022-3727/44/12/125405 . hal-00604890

\section{HAL Id: hal-00604890 https://hal.science/hal-00604890}

Submitted on 30 Jun 2011

HAL is a multi-disciplinary open access archive for the deposit and dissemination of scientific research documents, whether they are published or not. The documents may come from teaching and research institutions in France or abroad, or from public or private research centers.
L'archive ouverte pluridisciplinaire HAL, est destinée au dépôt et à la diffusion de documents scientifiques de niveau recherche, publiés ou non, émanant des établissements d'enseignement et de recherche français ou étrangers, des laboratoires publics ou privés. 


\title{
Growing imbedded $\mathrm{Ni}_{3} \mathrm{C}$ rich layer with sharp interfaces by means of ion beam mixing of $\mathrm{C} / \mathrm{Ni}$ layers.
}

Árpád Barna, László Kotis, János Lábár, Attila Sulyok, Attila L. Tóth, and Miklós Menyhárd Research Institute for Technical Physics and Materials Science

Budapest H-1525 PBOX 49, Hungary

Peter Panjan

Jožef Stefan Institute, Jamova 39, 1000 Ljubljana, Slovenia

\begin{abstract}
$\mathrm{C} / \mathrm{Ni}$ bilayers of various layer thicknesses $(20-40 \mathrm{~nm})$ were ion bombarded using $\mathrm{Ga}^{+}$and $\mathrm{Ni}^{+}$ projectiles with energies in the range of 20-30 keV. Ion bombardment resulted in the growth of a $\mathrm{Ni}_{3} \mathrm{C}$ rich layer with the following features: a. / sharp carbon / $\mathrm{Ni}_{3} \mathrm{C}$ rich layer interface $\mathrm{b}$. / the amount of $\mathrm{Ni}_{3} \mathrm{C}$ produced by the irradiation proportional to the square root of the fluence and depended on the type of projectile c. / good correlation between the distribution of vacancies produced by the ion bombardment and the distribution of the $\mathrm{Ni}_{3} \mathrm{C}$. The formation of the metastable $\mathrm{Ni}_{3} \mathrm{C}$ compound was explained by a vacancy assisted process. The sharp interface is the consequence of a relaxation process removing the intermixed $\mathrm{Ni}$ from the carbon layer. The square root of fluence dependence of the thickness of the $\mathrm{Ni}_{3} \mathrm{C}$ rich layer can be explained by a usual diffusion equation considering moving boundaries.
\end{abstract}




\section{INTRODUCTION}

There is a constant need for materials with desired physical and chemical behavior. This need can be, as least partially, fulfilled by non-equilibrium phases, which might exhibit unique, tailored features. Similarly, nano structures also display exceptional physical and chemical features. There are various methods which can be applied to produce non-equilibrium structures; one of them is ion bombardment, which can also be used for producing such structures in nano regions.

Ion irradiation of solid prompts a series of processes, like collisional events, large temperature increase in small volumes, radiation enhanced diffusion, chemically driven transport, etc, resulting in serious changes of the irradiated solid. One of the processes occurring during ion irradiation of a solid is ion beam mixing (IBM), which might cause the broadening of the originally abrupt interface between two pure materials by prompting the transport of the atoms from one pure region to the other [1-3]. IBM has been applied for producing tailored materials from the eighties [4]. Roughly speaking, the IBM process can be divided into two parts as a./ the mixing taking place due to collisional cascade, thermal spike etc initiated directly by the projectile b./ the relaxation of the highly non-equilibrium damaged region. The relaxation in many cases is terminated by a fast cooling period, consequently the damaged region generally does not reach equilibrium condition, rather it remains in a metastable state. A huge variety of metastable states can be observed ranging from miscible amorphous state [5] to the immiscible amorphous states $[6,7]$. The observed kinetics vary greatly too, the mass transport in limiting cases might be symmetric or asymmetric $[8,9]$. Applying focused ion beam (FIB) nano patterning of ion beam affected material is possible. Thus using ion bombardment, we can produce nano regions of non equilibrium material of the desired properties. 
Recently we have reported preliminary results of medium energy IBM experiments on a C/Ni system, which resulted in $\mathrm{Ni}_{3} \mathrm{C}$ rich layer exhibiting sharp interfaces [10]. $\mathrm{Ni}_{3} \mathrm{C}$ is a metastable compound with various applications; it can be used a. / to improve the mechanical behaviors of thin films $[11,12], \mathrm{b}$. / as template of hexagonal Ni for sensor application on the surface of nanotubes [13], c. / in nano architectures [14].

In this paper, we will give a more detailed description of the ion bombardment induced mixing of the $\mathrm{C} / \mathrm{Ni}$ interface applying different projectiles and ion energies. It will be shown that until reaching a critical fluence, the carbon/mixed layer (containing $\mathrm{Ni}_{3} \mathrm{C}$ ) interface remains sharp (despite the large carbon transport occurring through the interface). The amount of produced $\mathrm{Ni}_{3} \mathrm{C}$ depends on the square root of the fluence and the type of projectile besides the ion energy. We will also show that the alterations produced by the ion bombardment can only be explained by considering the relaxation processes taking place after primary mixing is terminated.

\section{EXPERIMENTAL}

$\mathrm{C} / \mathrm{Ni}$ multilayered specimens have been prepared by sequential sputter deposition of pure carbon and nickel on silicon (111) substrate. The nominal structures of the specimens were: specimen A; 3x(C $28 \mathrm{~nm} / \mathrm{Ni} 40 \mathrm{~nm}) / \mathrm{Si}$ substrate, specimen B; 3x(C $21 \mathrm{~nm} / \mathrm{Ni} 37 \mathrm{~nm}) / \mathrm{Si}$ substrate.

The actual structures of the specimens before and after irradiation were determined by cross sectional transmission electron microscopy (XTEM). The samples for XTEM studies were prepared by applying the usual procedure [15]; first mechanical polishing was applied, which was followed by $\mathrm{Ar}^{+}$-ion milling. XTEM images were taken by a Philips CM20 200 kV analytical microscope. 
The samples were irradiated by applying various energies and fluences of $\mathrm{Ga}^{+}$and $\mathrm{Ni}^{+}$ions. A $200 \times 200 \mu \mathrm{m}^{2}$ area of the specimens were irradiated by $\mathrm{Ga}^{+}$in a LEO $1540 \mathrm{XB}$ (FEG SEM FIB) cross beam system, using the Canion FIB optics. The area to be irradiated had been located using scanning electron microscopy (SEM) secondary electron image (SEI), and then checked on a single pass FIB SEI image. The angle of incidence of the irradiation was $5^{\circ}$ (with respect the surface normal). The energies of the $\mathrm{Ga}^{+}$projectiles were 20 and $30 \mathrm{keV}$, and the ion current density varied in the range of 3-20 nA/ $\mathrm{mm}^{2}$. The applied fluences, 0,25 , $50,100,200,400$ and $800 \mathrm{Ga}^{+} / \mathrm{nm}^{2}$, were determined by the time of the single pass irradiation.

10x10 mm sample was irradiated by $\mathrm{Ni}^{+}$in Rossendorf [16]. The angle of incidence of the irradiation was $0^{\circ}$, and energies of 20 and $30 \mathrm{keV}$ were applied.

Auger electron spectroscopy (AES) depth profiling was carried out in our dedicated systems by a STAIB DESA 100 pre-retarded CMA in direct current mode. The primary electron current was $30 \mathrm{nA}$ with a diameter of about $60 \mu \mathrm{m} .1 \mathrm{keV} \mathrm{Ar}^{+}$ions were used for AES depth profiling with angle of incidence of $74^{\circ}$ (with respect to the surface normal). The ion current was kept constant during sputtering. The sample was rotated (4 rev/ min) during ion bombardment. These parameters were chosen to minimize the ion bombardment induced surface and interface morphology development.

\subsection{Deriving elemental concentrations from the Auger peak intensities}

The shapes of the C Auger peaks in graphite and carbide strongly differ, thus the two phases can easily be separated. This way we could distinguish five constituents in the samples, those of $\mathrm{C}, \mathrm{Ni}, \mathrm{Si}, \mathrm{Ga}$ and $\mathrm{Ni}_{3} \mathrm{C}$. We used the usual relative sensitivity factor method for calculation of the concentrations [17]. To determine the relative sensitivity factors for our spectrometer and measurement conditions for the species above we followed various ways. There were always regions in the samples, which contained only pure C, Ni and Si. Using the Auger 
intensities measured in these regions we could determine directly the relative sensitivity factors of these elements. In the cases of $\mathrm{Ni}_{3} \mathrm{C}$ and $\mathrm{Ga}$, there were no pure regions, thus other solutions were applied. There were regions in the samples where only $\mathrm{Ni}_{3} \mathrm{C}$ and $\mathrm{Ni}$ were found. In these regions the decrease of the Ni signal (the shape of which is not affected by the chemical interaction) with respect to the pure Ni signal can be attributed to the presence of $\mathrm{C}$; this allows us to determine the amount of carbide present and thus the determination of the relative sensitivity factor of the $\mathrm{Ni}_{3} \mathrm{C}$ as well. The relative sensitivity factor of $\mathrm{Ga}$ was determined by fitting the measured numbers of $\mathrm{Ga}$ atoms to the implanted one in a sample where we could assume that all Ga projectiles remained in the sample. The same relative sensitivity factors were applied for all measured spectra.

In this system the volume density strongly varies (the volume densities of $\mathrm{Ni}$ and graphite are 91 and 113 atoms $/ \mathrm{nm}^{3}$, respectively). Thus, the AES depth profiles will not be given in the usual concentration vs. depth representation; rather the representation of volume densities (atoms $/ \mathrm{nm}^{3}$ ) vs. depth (nm) will be used. Having this representation, one can integrate the depth profile to result in the total numbers of atoms / unit area, which allows the comparison of the calculated number of atoms with those determined by XTEM.

\subsection{Calculation of the depth scale}

The procedure to be applied here has been published recently [18] and will only be shortly summarized as follows. In AES depth profiling, the number of atoms, $N_{\Delta t}^{i}$, of element $i$ removed from an area $A$ during time $\Delta t$ of ion bombardment is $N_{\Delta t}^{i}=A^{*} X_{i} * Y_{T}^{*} \Delta t * J$, where $X_{i}$ is the atomic concentration of element $i, Y_{T}$ is the total sputtering yield of sputtered material, and $J$ is the ion current density. It is assumed that the intermixed region is an ideal solution and thus the average atomic density of the mixture is $1 / \rho_{a}=\sum_{i}\left(X_{i} / \rho_{i}\right)$, where $\rho_{i}$ is the atomic density of pure element $i$. The total sputtering yield of the mixture was assumed to 
be $Y_{T}=\sum_{i}\left(X_{i} Y_{i}\right)$, where the $Y_{i}$ is the partial sputtering yield of element $i$. Though it is well known that this equation is generally not valid [19], we used it since Transport Range of Ions in Matter (SRIM) [20] simulation predicted an error of less then $20 \%$. The number of atoms in the unaltered layers, assuming nominal densities, is known from the XTEM studies, which provides the thickness of layers. The calculated (from AES depth profile) and measured (by XTEM) number of atoms can be equaled for a given layer providing the ion current density. Using this value, we have the depth scale. The samples have four layers, which have not been affected by the implantation. We always calculated the number of atoms in the unaltered layer as well. Using the above procedure the deviation of the calculated and measured (by XTEM) numbers of atoms in the four unaltered layers were less than $6 \%$, proving the validity of the method.

\section{Results}

\subsection{XTEM results}

XTEM imaging was used to characterize the initial and final (irradiated) structures of the samples. Figure 1 shows the XTEM image of the as received sample B. The image shows that the $\mathrm{Ni}$ and $\mathrm{C}$ layers are polycrystalline and amorphous, respectively. The interfaces are flat. The intrinsic rms roughness of the interfaces was estimated, based on the XTEM images, to be less than $1 \mathrm{~nm}$. Similar results were obtained in case of the as received sample A as well. In figure 2 the XTEM image of sample B irradiated by $200 \mathrm{Ni}^{+}(20 \mathrm{keV}) / \mathrm{nm}^{2}$ is shown. Only the top $\mathrm{C}$ and following $\mathrm{Ni}$ layers were affected by the irradiation. In the first $\mathrm{C}$ layer a broad distribution of heavier atoms (darker contrast would be identified as $\mathrm{Ni}$, see later) appeared. In the first Ni layer we could identify a new layer with lower contrast. The detailed chemical analysis of the sample was carried out by applying AES depth profiling. The rms roughness of 
the $\mathrm{C}$ / new layer interface seemed to be somewhat higher than that of the intrinsic $\mathrm{C} / \mathrm{Ni}$ interface, but it is still less than $1 \mathrm{~nm}$.

\subsection{AES depth profiling results}

Figure 3 (a) shows the whole as measured AES depth profile recorded on sample B irradiated by $200 \mathrm{Ni}^{+}(20 \mathrm{keV}) / \mathrm{nm}^{2}$. Carbon being in carbide and graphite are shown separately; $\mathrm{Ni}_{3} \mathrm{C}$ and $\mathrm{C}$ stand for the Auger signal emitted by $\mathrm{Ni}_{3} \mathrm{C}$ and graphite, respectively. Figure 3 a shows that only the first $\mathrm{C}$ (counted from the free surface) and the following Ni layers are affected by the irradiation; thus in the following we will show only this part of the depth profiles. Figure $3 \mathrm{~b}$ shows, in good agreement with the XTEM image, that the Ni irradiation caused the formation of a./ a broad $\mathrm{Ni}$ enriched region in the $\mathrm{C}$ layer (part of the $\mathrm{Ni}$ is in $\mathrm{Ni}_{3} \mathrm{C}$ form); b./ $\mathrm{Ni}_{3} \mathrm{C}$ rich zone in the originally pure $\mathrm{Ni}$ layer, where we cannot detect graphite (our detection level is about $4 \%$ ). The interface between the $\mathrm{C}$ layer and the $\mathrm{Ni}_{3} \mathrm{C}$ rich zone is abrupt. If $\mathrm{Ga}^{+}$ irradiation is applied, as shown in figure 4, the $\mathrm{Ni}_{3} \mathrm{C}$ carbide formation in the Ni layer is similar to the previous one.

We have carried out many experiments varying the projectiles $\left(\mathrm{Ga}^{+}\right.$and $\left.\mathrm{Ni}^{+}\right)$, their energies and the samples. In the following, as examples, some typical results will be summarized. First in figure 5 (a) and (b) we show the $\mathrm{Ni}_{3} \mathrm{C}$ density distributions for sample $\mathrm{B}$ applying $\mathrm{Ni}^{+}$ and $\mathrm{Ga}^{+}$irradiations, respectively. The applied fluences (numbers of ions $/ \mathrm{nm}^{2}$ ) / ion energies $(\mathrm{keV})$ are shown in the figures. The depth scales are shifted to have the $\mathrm{C} / \mathrm{Ni}_{3} \mathrm{C}$ transitions at the depth where the original (non-irradiated ) C/Ni interface is. Figures 6 (a) and (b) show the $\mathrm{Ni}$ (all Ni being in carbide and metallic form) and $\mathrm{C}$ density distributions, for various fluences applying $\mathrm{Ga}^{+}$irradiations. In figure 7, we show the $\mathrm{Ni}$ (all $\mathrm{Ni}$ in carbide and metallic form) density distributions after $\mathrm{Ni}^{+}$irradiation with various fluences; the fluences (units number of $\mathrm{Ni}^{+} / \mathrm{nm}^{2}$ ) applied are given in the figure. Last, in figure 8 , we show the total amount of $\mathrm{Ni}_{3} \mathrm{C}$ $/ \mathrm{nm}^{2}$ formed applying $\mathrm{Ni}^{+} / 20 \mathrm{keV}, \mathrm{Ga}^{+} / 20 \mathrm{keV}$ and $\mathrm{Ga}^{+} / 30 \mathrm{keV}$ irradiations of sample $\mathrm{B}$ as a 
function of the square root of the applied fluence. Similar results were obtained if sample A was irradiated.

\section{DISCUSSION}

In the discussion we will address two questions a./ how can a sharp $\mathrm{C} / \mathrm{Ni}_{3} \mathrm{C}$ rich layer interface form, b./ how can we describe the growth of the $\mathrm{Ni}_{3} \mathrm{C}$ rich layer. In both cases we will deal with a one dimensional problem.

4.1 Formation of the sharp interface between the carbon and the $\mathrm{Ni}_{3} \mathrm{C}$ rich layer.

Figure $6 \mathrm{a}$ and $\mathrm{b}$ shows that there is a sharp interface between the $\mathrm{C}$ and $\mathrm{Ni}$ (containing $\mathrm{Ni}_{3} \mathrm{C}$ ). This means that a considerably amount of carbon is transport to the Ni layer, while the Ni transport to the carbon layer is negligible, that is, the material transport during the ion bombardment process is strongly asymmetric.

Asymmetric nature of material transport in the course of IBM has been demonstrated long time ago. Norlund et al. [8] studied the IBM of $\mathrm{Co} / \mathrm{Cu}$ and $\mathrm{Ni} / \mathrm{Cu}$ layers by means of molecular-dynamics simulation. They found that the production of vacancies and interface roughening is asymmetrical; more $\mathrm{Cu}$ is introduced into the $\mathrm{Co}$ or $\mathrm{Ni}$ layers than vice versa, and more vacancies are produced in the $\mathrm{Cu}$ layer than that in $\mathrm{Co}$ and $\mathrm{Ni}$ layers. The asymmetric mixing was explained by the lower melting point of $\mathrm{Cu}$. Chang et al. predict that the elements of lower cohesive energy are more mobile causing the asymmetric mixing [9]. These explanations, however, are not applicable for our case, where $\mathrm{C}$ with much higher melting point and cohesive energy than those of $\mathrm{Ni}$, seems to be the more mobile species. Stepanova developed a phenomenological model to describe the asymmetric mixing considering the kinematical factors as well as the changed sputtering yield due to compound formation $[21,22]$. However, the asymmetry found in our case is so high, that it is unlikely that one could find parameters using of which the given calculation would describe our case. 
Ballistic model based simulations generally predict that a sharp interface (two pure materials in contact) broadens due to the ion bombardment resulting in an error function concentration distribution. The parameter of the error function increases with fluence. This is exactly the picture suggested by the SRIM [20] simulation (based on ballistic model) if we apply it for our case. It predicts that $\mathrm{C}$ enters to the Ni layer and $\mathrm{Ni}$ appears in the $\mathrm{C}$ layer as well. The broadening of the interface is more or less symmetrical. The SRIM simulation cannot account for the accumulation of the defects during the ion bombardment. The more refined TRIDYN (TRIDYN_FZR, FZR-317 [23]) simulation (also based on ballistic model) gives a more detailed description. According to the TRIDYN simulation, Ni penetrates to the carbon layer and its penetration distance and concentration increase with fluence. Thus, the results of both simulations disagree with the experimental finding, which shows a strongly asymmetric material transport.

To understand our results we should first emphasize that AES depth profiling as well as the XTEM show the condition of the material after the final stable or metastable state is reached; thus, we study the condition after ion mixing and possible relaxation. To explain the asymmetrical material transport found in our case let us first consider the measured penetration of the projectiles.

The distributions of the implanted Ga measured on sample B using various fluences at $20 \mathrm{keV}$ irradiation energy are summarized in figure 9. The actually measured Ga densities are multiplied to help the easier comparison of the curves (see later). The shape of the Ga distribution is characterized by a maximum at the interface. In the figure, we also show (by a line) the shape of the Ga distribution according to SRIM simulation (applying the same bombardment conditions on the same sample structure). The simulated Ga penetration also shows the maximum at the interface. The maximum based on the simulation can be explained by the lower projected range of $\mathrm{Ga}^{+}$in the $\mathrm{Ni}$ layer $(7.2 \mathrm{~nm})$ than that in the $\mathrm{C}$ layer $(17.7 \mathrm{~nm})$. 
Because of the difference of the projected ranges, $\mathrm{Ga}$ accumulation at the interface is expected.

The measurement of the implanted Ni distribution is not so straightforward since we cannot distinguish between the implanted $\mathrm{Ni}$ and those originally in the Ni layer. Thus, we are restricted to the measurement of the $\mathrm{Ni}$ distribution in the $\mathrm{C}$ layer. The atomic numbers of $\mathrm{Ni}$ (28) and Ga (31) are only slightly different, thus Ni penetration and the mixing it causes should be similar to that of Ga. This is really the case if we consider the ballistic model. In figure 7, we show the Ni distribution (by a line) according to the SRIM simulation. The shape is similar to that of Ga distribution shown in figure 9. The maximum at the interface is explained similarly as before; the projected ranges of $\mathrm{Ni}^{+} / 20 \mathrm{keV}$ are 18.8 and 7.7 , in $\mathrm{C}$ and $\mathrm{Ni}$, respectively. Thus, we expect that the distribution of the implanted Ni would be similar to that of Ga. However, according to figure 7 the Ni distribution is strongly different from that of $\mathrm{Ga}$. It shows, at any fluence, a maximum within the $\mathrm{C}$ layer. Leaving the maximum toward the interface the $\mathrm{Ni}$ concentration strongly decreases. Close to the $\mathrm{C} / \mathrm{Ni}_{3} \mathrm{C}$ rich layer interface the $\mathrm{Ni}$ concentration is low; at lower $\mathrm{Ni}^{+}$fluences it even vanishes. Such behavior is completely absent in the Ga distribution. This type of distribution can neither be explained by the primary penetration of the $\mathrm{Ni}$, nor with ion mixing, which supposes the transport of $\mathrm{Ni}$ to the $\mathrm{C}$ layer. We can explain this distribution, however, assuming that after the primary processes (primary ion penetration and ion mixing), during the relaxation process, desegregation occurs; all $\mathrm{Ni}$ transported into $\mathrm{C}$ either as primary ions or mixed atoms in some vicinity of the $\mathrm{C} / \mathrm{Ni}$ interface, return either to the Ni layer or the $\mathrm{Ni}$ enriched region of the $\mathrm{C}$ layer.

Exactly the same desegregation process should occur in the case of Ga irradiation. Based on the SRIM simulation it is clear that the IBM drives the $\mathrm{Ni}$ atoms to the $\mathrm{C}$ layer into a 2-3 nm thick layer. If the mixed $\mathrm{Ni}$ atoms remain there then if the next cascade hits that region 
(containing mixed $\mathrm{Ni}$ ) it drives the $\mathrm{Ni}$ atoms even deeper. The TRIDYN simulation predicts such a process, which is resulted in Ni penetration into the $\mathrm{C}$ layer. The missing $\mathrm{Ni}$ penetration (figures $2,4,6$ ) can only be explained by the Ni desegregation, which should occur before the next cascade.

Similar explanation was applied for the IBM of $\mathrm{Ag} / \mathrm{Fe}$ system. In that system the high energy ion irradiation resulted in much less interface broadening than that expected based on the ballistic model; to explain this result, it was supposed that the ballistic mixing is followed by a demixing process $[24,25]$.

\subsection{The growth of $\mathrm{Ni}_{3} \mathrm{C}$ layer}

Figures $5 \mathrm{a}$ and $\mathrm{b}$ show that the density of the $\mathrm{Ni}_{3} \mathrm{C}$ does not depend on the fluence (except the lowest fluences) applying either $\mathrm{Ni}^{+}$or $\mathrm{Ga}^{+}$projectiles. The (constant) density of $\mathrm{Ni}_{3} \mathrm{C}$ depends on the projectile, however. The thickness of the $\mathrm{Ni}_{3} \mathrm{C}$ rich layer, with constant $\mathrm{Ni}_{3} \mathrm{C}$ density, increases with increasing fluence. This process is similar to any heterogeneous compound formation on a surface e.g. silicon oxidation [26] or when melting or solidification occurs. In all these cases, the diffusion driven material transport results in a moving boundary [27]. The corresponding differential equation (Stefan problem [27]) is Fick's second equation (in one dimension):

$$
\frac{\partial c}{\partial t}=D \frac{\partial^{2} c}{\partial x^{2}}
$$

where the boundary conditions at the two interfaces are

$$
\frac{\partial c}{\partial x}=H(c-1)_{x=0} \quad \frac{\partial c}{\partial x}=\left.k \frac{d s}{d t}\right|_{x=s(t)}
$$

$c$ is the concentration of the reactant, $s(t)$ is the coordinate of the moving boundary $H$ and $k$ are parameters describing the input and reaction of the reactant at the interfaces (the initial 
surface is fixed at $x=0$ ). According to the equations there is no compound formation in the reacted zone $(0<x<s(t))$, which is saturated, thus the current of reactant entering at $x=0$, is completely consumed at $x=s(t)$. The solution of this equation provides $s(t)$, that is, the growth of the reacted zone as a function of time. In steady state condition $\left(\partial^{2} c / \partial x^{2}=0\right)$ the solution of equation (1) gives $s(t) \sim t$ and $s(t) \sim V_{t}$ dependencies for low and high $t$, respectively. In materials science, the most famous application of this equation is most likely the Deal-Grove equation describing the oxidation of silicon [26].

Desimoni et al. [28] applied the same equation for the description of compound formation during ion bombardment. In their approach, adsorption was replaced by the bombardment induced current. They considered asymmetric and symmetric mixing as well. On the other hand, they did not consider the actual concentration distribution, rather only the amount of reacted material has been calculated.

Considering our present experiment, for the first glance, this equation seems to work properly. A closer look reveals some problems, however. Equation (1) assumes strong compound formation (phase change) at the $s(t)$ interface, and no compound formation in $(0<x<s(t))$ region, which is saturated. However, in our case a./ the $\mathrm{Ni}_{3} \mathrm{C}$ is a metastable compound with positive heat of formation, b./ in the $0<x<s(t)$ region there is $\mathrm{Ni}+\mathrm{Ni}_{3} \mathrm{C}$, that is, the reacted region is not saturated by $\mathrm{Ni}_{3} \mathrm{C}$, c./ the compound- (undamaged) matrix interface is not sharp. In the following, we show that despite of these, seemingly contradictory facts, our system meets with the requirements above and the layer growth is similar to any heterogeneous reaction.

\subsubsection{Formation of $\mathrm{Ni}_{3} \mathrm{C}$.}

The heat of formation of $\mathrm{Ni}_{3} \mathrm{C}$ is in the range of $+0.02-+0.05 \mathrm{eV}$ determined by experiment [29], and theory [30]; thus it is a metastable compound which cannot be formed in equilibrium conditions. Ion beam mixing is far from being an equilibrium process and thus it 
can overcome the problem above. Really, IBM is frequently applied to produce various nonequilibrium phases like amorphous alloys with negative or positive heat of mixing [1-9]. To explain these phenomena it is frequently argued that the fast quenching is responsible for the process. There are, however, explanations that are more refined. It was observed that multilayer systems of immiscible elements could be converted by IBM to amorphous nonequilibrium alloys [6,7]. In these cases the total energy of the system decreases despite of the positive heat of formation of the alloy, since the mixing removes the high energy interfaces. We can also find similar explanation for our case. We assume that the metastable $\mathrm{Ni}_{3} \mathrm{C}$ forms according to the following chain of reactions:

$\mathrm{Ni}=\mathrm{Ni}($ int $)+\mathrm{Ni}(\mathrm{vac})\left(\right.$ due to $\mathrm{Ga}^{+}$or/and $\mathrm{Ni}^{+}$bombardment $)$

$3 \mathrm{Ni}+\mathrm{Ni}($ vac $)+\mathrm{C}($ int $)=\mathrm{Ni}_{3} \mathrm{C}$

adding the two equation gives

$4 \mathrm{Ni}+\mathrm{C}=\mathrm{Ni}_{3} \mathrm{C}+\mathrm{Ni}(\mathrm{int})$

where int and vac stand for interstitial and vacancy, respectively. The experimentally reported formation energy of the self vacancy of $\mathrm{Ni}$ is in the range of 1.3- $1.85 \mathrm{eV}$ [31]. The formation energy of $\mathrm{Ni}_{3} \mathrm{C}$ is $+0.02-0.05 \mathrm{eV}[29,30]$. We have not found data for the energy of the $\mathrm{C}$ interstitial in $\mathrm{Ni}$, but it should be positive. The energy of Ni(int) is supplied by the ion beam. Thus, the energy balance is negative, since a high energy vacancy is annihilated in the reaction, and thus the formation of the $\mathrm{Ni}_{3} \mathrm{C}$ compound is energetically favorable.

\subsubsection{Layer growth}

According to eq. $2 \mathrm{~b}$, compound formation is only possible in regions where vacancies are available. The $\mathrm{Ga}^{+}$and $\mathrm{Ni}^{+}$projectiles evidently produce vacancies. The amount of vacancies is calculated by the ballistic models. The actual vacancy concentration is somewhat uncertain, however, since the ballistic models do not consider the relaxation processes. Experimentally we cannot measure the vacancy distribution. The projectile distribution can be measured, 
however, and it is accepted that the vacancy distribution correlates with it; thus based on the projectile distribution we can estimate the vacancy distribution. The Ga distributions were measured, and are shown in figure 9. The measured densities are multiplied by factors given in the figure to make the comparison easier.

The depth distributions of Ga produced by various fluences in the range of $100-400 \mathrm{Ga}^{+} / \mathrm{nm}^{2}$ (a factor of 4 change in fluence) are rather similar. In case of fluence $600 \mathrm{Ga}^{+} / \mathrm{nm}^{2}$ a new feature also appears, while at low fluence $\left(50 \mathrm{Ga}^{+} / \mathrm{nm}^{2}\right)$ the signal is too much noisy for comparison.

The similarities of the Ga distributions can be explained by considering that at these bombardment conditions the carbon sputtering yield is low, consequently the thickness of the carbon layer only slightly decreases, which decrease is balanced by the presence of the implanted $\mathrm{Ga}$ atoms. Therefore, the penetration of the Ga does not change strongly as a function of fluence, thus the shape of the Ga distribution also does not change as a function of fluence if we are in the given fluence range. That is, the only change with increasing fluence is the density increase of the Ga, maintaining the same shape. At higher fluence ranges, where the removal of the carbon cannot be neglected, the Ga distribution begins to change. From the point of view of vacancy production we suppose that a threshold concentration of vacancies necessary for compound formation. Since the vacancy concentration correlates with the Ga concentration, the Ga concentration should exceed also a threshold concentration for the compound production. It also follows that the thickness of the compound should increase with increasing fluence, since the necessary threshold density of Ga moves deeper with increasing fluence; consequently there should be a correlation between the Ga penetration and carbide formation. This is really the case. In figure 10 we show the $\mathrm{Ga}$ and $\mathrm{Ni}_{3} \mathrm{C}$ density distributions as a function of depth for fluences ranging from $50 \mathrm{Ga}^{+} / \mathrm{nm}^{2}$ to $600 \mathrm{Ga}^{+} / \mathrm{nm}^{2}$. To show the relative position of the $\mathrm{Ga}$ and $\mathrm{Ni}_{3} \mathrm{C}$ distributions, the distributions are shifted to 
have the same depth for the $\mathrm{Ni}_{3} \mathrm{C} /$ pure $\mathrm{Ni}$ transitions. It is clear that relative position of the two distributions is unchanged while the fluence increases by more than a factor of 10 . This correlation supports the assumption that compound formation occurs if the vacancy concentration exceeds a threshold value.

The same vacancy-mediated $\mathrm{Ni}_{3} \mathrm{C}$ formation process is responsible for the projectile dependent $\mathrm{Ni}_{3} \mathrm{C}$ density; figures $5 \mathrm{a}$ and $\mathrm{b}$ show that applying the same bombarding energy $\mathrm{Ni}$ irradiation results in higher concentration of the $\mathrm{Ni}_{3} \mathrm{C}$ than that produced by $\mathrm{Ga}$ irradiation. Though the two projectiles are rather similar, SRIM calculation predicts more vacancies in the $\mathrm{Ni}$ for $\mathrm{Ni}^{+}$irradiation than that for $\mathrm{Ga}^{+}$irradiation. This also supports the assumption that the number of created vacancies determines the compound formation.

We can also account for the problem of saturation. Obviously if there are no more vacancies available the reaction stops. Thus, the saturation in the $0<x<s(t)$ region is connected to the lack of vacancies and not to the availability of $\mathrm{Ni}$ atoms; the coexistence of the $\mathrm{Ni}_{3} \mathrm{C}$ and $\mathrm{Ni}$ does not mean that the region is not saturated.

The fluence dependence of the $\mathrm{Ni}_{3} \mathrm{C}$ can also be explained. Figure 8 shows the total amount of $\mathrm{Ni}_{3} \mathrm{C}$ produced as a function of square root of fluence. It is clear that there is a square root of fluence, $\sqrt{ } \Phi$, dependence if the fluence is higher than $100 \mathrm{Ga}^{+} / \mathrm{nm}^{2}$ and $80 \mathrm{Ni}^{+} / \mathrm{nm}^{2}$, respectively, agreeing with the prediction of equation (1). At low values deviation occurs from this dependence, which might be explained by experimental inaccuracies (the AES depth profiling also makes carbides) or according to equation (1), which predicts at lower fluences, a linear fluence dependence instead of the square root one. The coefficients of the two dependencies are different, thus the fluence dependence of compound formation shown in figure 8 might be also explained by equation (1).

The usual solutions of the Stephan problem predict sharp transitions on both interfaces. These can be accepted if we deal with melting or compound production of high energy of formation. 
Even in these cases the discontinuous concentration distribution poses mathematical problems. It has been shown, however, that supposing a homogeneous reaction, a broad interface on the growing side [32] is possible, as in our case.

Summarizing; the observed compound formation was found to be a vacancy assisted solid state reaction, and the kinetics of the growth of the compound layer is described by equation (1). This process is expected to occur for other material pairs as well, where the above conditions apply. E.g. we have observed that the irradiation of $\mathrm{Si} / \mathrm{Cr}$ layer pair by $30 \mathrm{keV} \mathrm{Ga}{ }^{+}$ ions also resulted in a broad intermixed layer with sharp interface [33].

In this experiment applying broad or/and overlapping ion beams, we have produced an imbedded layer containing a non-equilibrium compound, which allowed an easy structure and chemical characterization. Obviously, using the same arrangement but applying finely focused ion beam and irradiating not overlapping regions, one can produce nano particles of desired size (limited by the beam size). The lateral arrangement of the imbedded nano particles can follow any tailored pattern because of the versatile control of the FIB.

\section{Conclusions}

The interface of $\mathrm{C} / \mathrm{Ni}$ bilayer was bombarded using $\mathrm{Ga}^{+}$and $\mathrm{Ni}^{+}$projectiles of energies in the range of 20-30 keV. The ion bombardment resulted in a asymmetric material transport, $\mathrm{C}$ had been transported to $\mathrm{Ni}$, but not vice versa. Because of the asymmetric material transport, the carbon/ $/ \mathrm{Ni}_{3} \mathrm{C}$ rich layer interface was found to be sharp. The carbon transported to the Ni layer formed metastable $\mathrm{Ni}_{3} \mathrm{C}$ compound. The concentration of the $\mathrm{Ni}_{3} \mathrm{C}$ compound depended on the type of projectile. With increasing fluence only the thickness of the $\mathrm{Ni}_{3} \mathrm{C}$ rich layer increased but not the concentration of the $\mathrm{Ni}_{3} \mathrm{C}$. The total amount of $\mathrm{Ni}_{3} \mathrm{C}$ produced by the irradiation was found to be proportional to the square root of the fluence at lager fluence values. 
The sharp carbon/ $\mathrm{Ni}_{3} \mathrm{C}$ rich layer interface could be explained by relaxation processes; the $\mathrm{Ni}$ transported into the $\mathrm{C}$ layer by the cascade mixing, returns to the Ni layer by means of desegregation. Metastable $\mathrm{Ni}_{3} \mathrm{C}$ formation was explained by a vacancy mediated process, while the fluence dependence of the layer growth can be described by diffusion equation considering a moving boundary.

\section{Acknowledgements}

Ni irradiation was made possible by the AIM - Center for Application of Ion Beams to Materials Research, RITA Contract No. 025646.

\section{References}

1. Cheng YT, 1990 Mater. Sci. Rep. 545

2. Nastasi N and J.W. Mayer 1994 Materials Science and Engineering R12 1

3. Bolse W 1994 Mater. Sci. Eng. R12 53

4. Part III in MRS Proceedings 1989Vol. 157 Beam-Solid Interactions; Physical Phenomena (Eds. J.A.Knapp, P. Borgesen, R.A.Zuhr)

5. Milosavljevic M, Shao G, Bibic N, McKinty CN, Jeynes C and Homewood KP 2002 Nucl. Instrum. Meth. B 188166

6. Yan HF, Shen YX, Guo HB and Liu B X 2007 J. Phys.: Condens. Matter 19 026219

7. Amirthapandian S, Panigrahi BK, Rajagopalan, Gupta SA, Nair KGM, R Nandedkar RV and Narayanasamy A 2004 Phys Rev B 69165411 
8. Nordlund K and Averback RS 1999 Phys Rev B 5920

9. Chang GS, Jung SM, Song JH, Kim HB, Woo JJ, Byun DH and Whang CN 1997 Nucl. Instrum. Meth. B 121244

10. Barna A, Kotis L, Lábár J, Osváth Z, Tóth AL, Menyhard M, Zalar A, Panjan P 2009 J. Appl. Phys. 105044305

11. Kukiełka S, Gulbiński W, Pauleau Y, Dub SN, Grob JJ, 2006 Surface and Coating Tech. 2006258

12. Ujvari,T Toth A, Kovacs GJ, Safran G.,Geszti O Radnoczi G, Bertoti, 2004 Surf. Interfac. Anal. 36760

13. Hwang JY, Singh ARP, Chaudhari M, Tiley J, Zhu Y, Du J, Banerjee R, $2010 \mathrm{~J}$. Phys. Chem. C 11410424

14. Wei Zhou, Kun Zheng, Lin He, Rongming Wang, Lin Guo, Chinping Chen,Xiaodong Han, and Ze Zhang, 2008 Nano Letters, 81147

15. Barna A, Radnóczi G, Pécz B 1997 Sample Preparation Techniques for TEM, in Handbook for Microscopy, vol. 3./ Applications: II. Special Topics ed. by S.

Amelickx et al, (VCH Verlaggesellschaft mbH, Weinheim, Germany) Chapter 3. pp: $751-801$

16. AIM - Center for Application of Ion Beams to Materials Research, RITA Contract No. 025646.

17. Handbook of Auger Electron Spectroscopy, Third Edition, 1995 Eds. K.D. Childs, B.A. Carlson, L.A. LaVanier, J.F. Moulder, D.F. Paul, W.F. Stickle, D.G. Watson Eden Prairie, Minnesota

18. Kotis L, Menyhard M, Sulyok A, Sáfrán G, Zalar A, Kovac J and Panjan P 2009 Surf. Interface Anal. 41799 
19. Sigmund P 1981 in Sputtering by Particle Bombardment I Top. Appl. Phys., 47th ed., (edited by R. Behrisch ) Springer, Berlin, pp60-65

20. SRIM Transport Range of Ions in Matter by J. F. Ziegler. Software freely available www.srim.org

21. Stepanova MG 1995 Nucl. Instrum. Meth. B 95481

22. Stepanova MG 1996 Surf. Interface Anal. . 24416

23. TRIDYN_FZR, FZR-317, W. Möller and M. Posselt, Forschungzentrum Rossendorf, 01314 Dresden, Germany.

24. Crespo-Sosa A, Schaaf P, Bolse W, Lieb KP, Gimbel M, Geyer U, Tosello C, 1996 Phys. Rev. B $\mathbf{5 3} 14795$

25. Neubauer M, Lieb KP, Uhrmacher M, Wodniecki P,1998 Europhys. Lett. 43177

26. Deal BE, Grove AS 1965 J. Appl. Phys. 363770

27. Gupta SC 2003 The classical Stefan problem Noth-Holland series in Applied mathematics and Mechanics, Elsevier

28. Desimoni J and Traverse A 1993 Phys. Rev. B 4813266

29. Meschel SV and.Kleppa OJ 1997 J. Alloys Comp. 257227

30. Miedema AR, Niessen AK, De Boer FR, Boom R and Matterns WCM, Cohesion in Metals: Transition Metal Alloys ( North-Holland, Amsterdam, 1989)

31. Kraftmaker Y 1998 Physics Reports 29979

32. Evans JD, King JR 2000 SIAM J. Appl. Math. 601977

33. Barna A, Kotis L, Lábár J, Osváth Z, Tóth AL, Menyhard M, Zalar A, Panjan P 2007 J. Appl. Phys. 102053513 
Figure captions

1. XTEM image of the as received sample B.

2. XTEM image of irradiated sample B. Irradiation: $\mathrm{Ni}^{+}, 20 \mathrm{keV}, 200$ ions $/ \mathrm{nm}^{2}$.

3. a. The whole as measured AES depth profile (Auger signal vs. sputtering time) of sample B irradiated by $\mathrm{Ni}^{+}\left(20 \mathrm{keV}, 200\right.$ ions $\left./ \mathrm{nm}^{2}\right)$. b. The beginning part of the profile shown in figure 3 a.

4. The as measured AES depth profile of sample B irradiated by $\mathrm{Ga}^{+}(20 \mathrm{keV}, 200$ ions $\left./ \mathrm{nm}^{2}\right)$.

5. $\mathrm{Ni}_{3} \mathrm{C}$ density profile measured on sample B. a. projectile $\mathrm{Ni}^{+}(20 \mathrm{keV})$. b projectile $\mathrm{Ga}^{+}$. The parameters in the figure are the fluences (unit, numbers of ions $/ \mathrm{nm}^{2}$ ) and energies applied.

6. The $\mathrm{Ni}(\mathrm{a})$ and $\mathrm{C}(\mathrm{b})$ density profiles in case of $\mathrm{Ga}^{+}(20 \mathrm{keV})$ irradiation. The parameters in the figure are the fluences (unit, numbers of $\mathrm{Ga}^{+}$ions $/ \mathrm{nm}^{2}$ ) applied.

7. The Ni density profiles for $\mathrm{Ni}^{+}(20 \mathrm{keV})$ irradiation. The parameters in the figure are the fluences (unit, numbers of $\mathrm{Ni}^{+}$ions $/ \mathrm{nm}^{2}$ ) applied. The line shows the shape of the Ni distribution according to SRIM simulation.

8. The total amount of $\mathrm{Ni}_{3} \mathrm{C} / \mathrm{nm}^{2}$ produced by various projectiles and energies as a function of the square root of fluence (unit, numbers of ions $/ \mathrm{nm}^{2}$ ).

9. The Ga density profile in sample $\mathrm{B}$ at $20 \mathrm{keV} \mathrm{Ga}^{+}$bombardment. The measured density values are multiplied by the factors shown in the figures to make the comparison easier. The parameters in the figure are the fluences (unit, numbers of $\mathrm{Ga}^{+}$ ions $/ \mathrm{nm}^{2}$ ) applied. The line shows the shape of the Ga distribution given by SRIM simulation.

10. The Ga (line) and carbide (symbol) density profiles. Parameters in the figure are the fluences (unit, numbers of $\mathrm{Ga}^{+}$ions $/ \mathrm{nm}^{2}$ ) applied. Sample $\mathrm{B}, \mathrm{Ga}^{+} 20 \mathrm{keV}$. The 
distributions are shifted to have the same depth for the $\mathrm{Ni}_{3} \mathrm{C} /$ pure $\mathrm{Ni}$ transitions. 
Figures

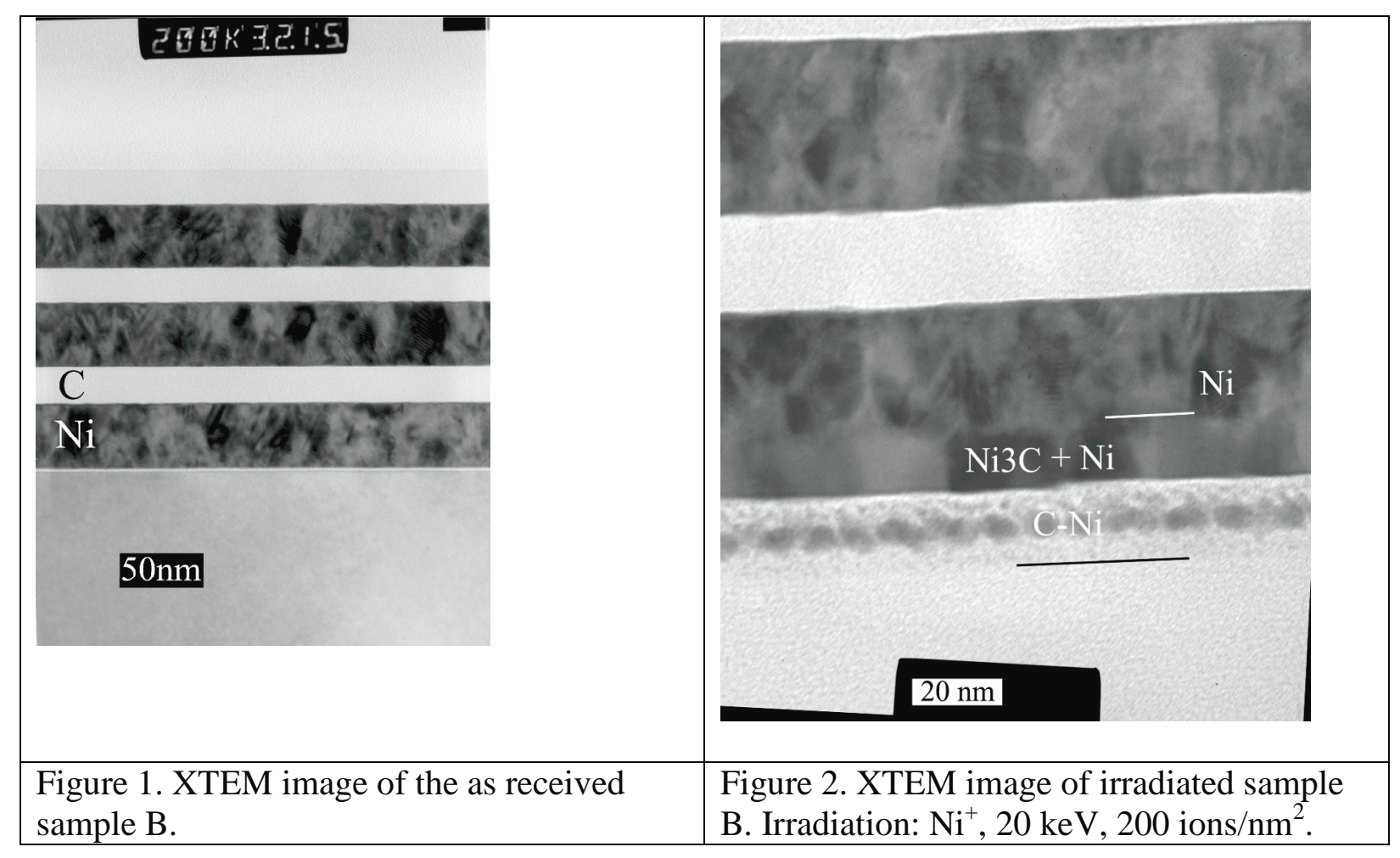


(a)

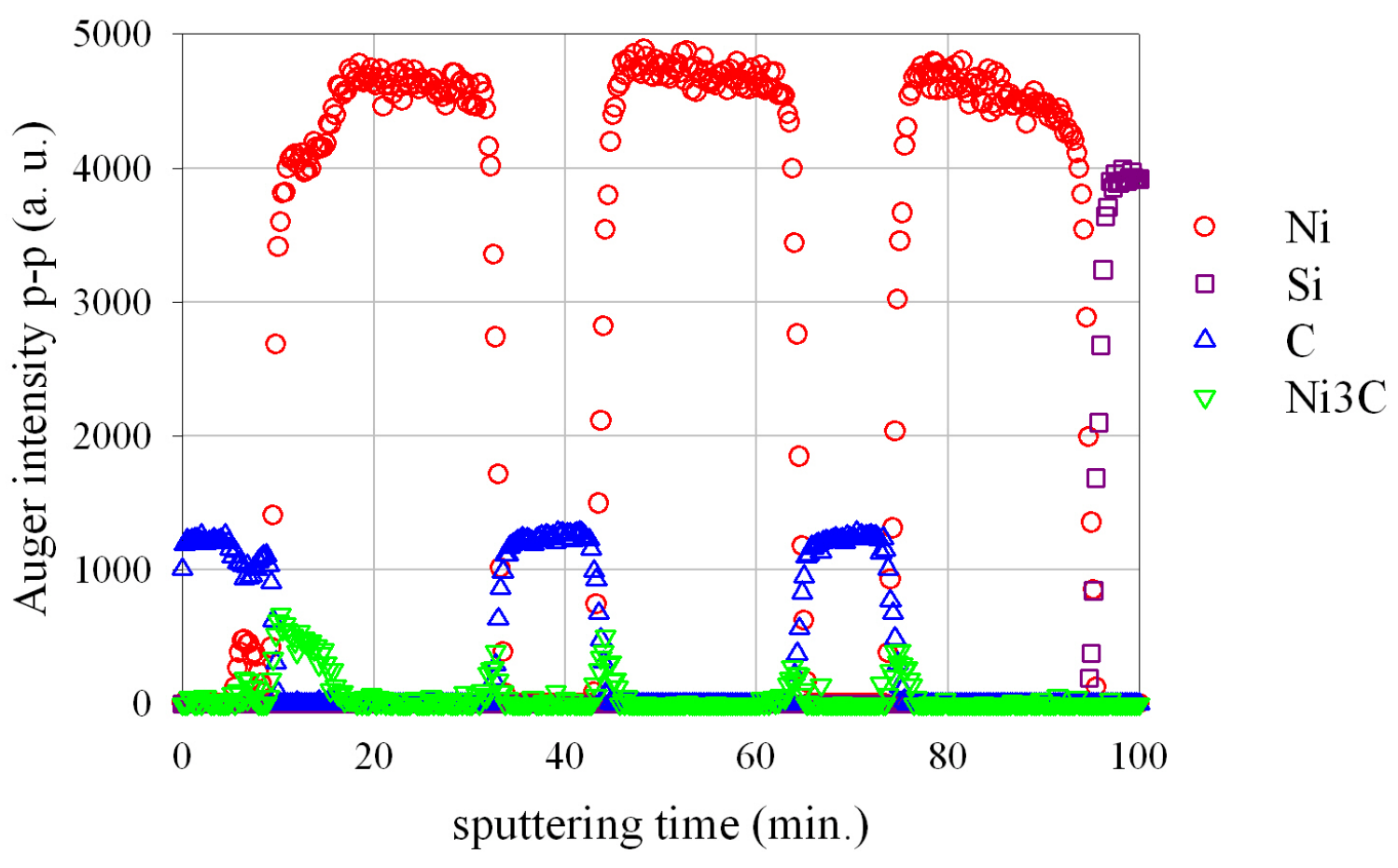

Figure 3. a The whole as measured AES depth profile (Auger signal vs. sputtering time) of sample B irradiated by $\mathrm{Ni}^{+}\left(20 \mathrm{keV}, 200\right.$ ions $\left./ \mathrm{nm}^{2}\right)$.

(b)

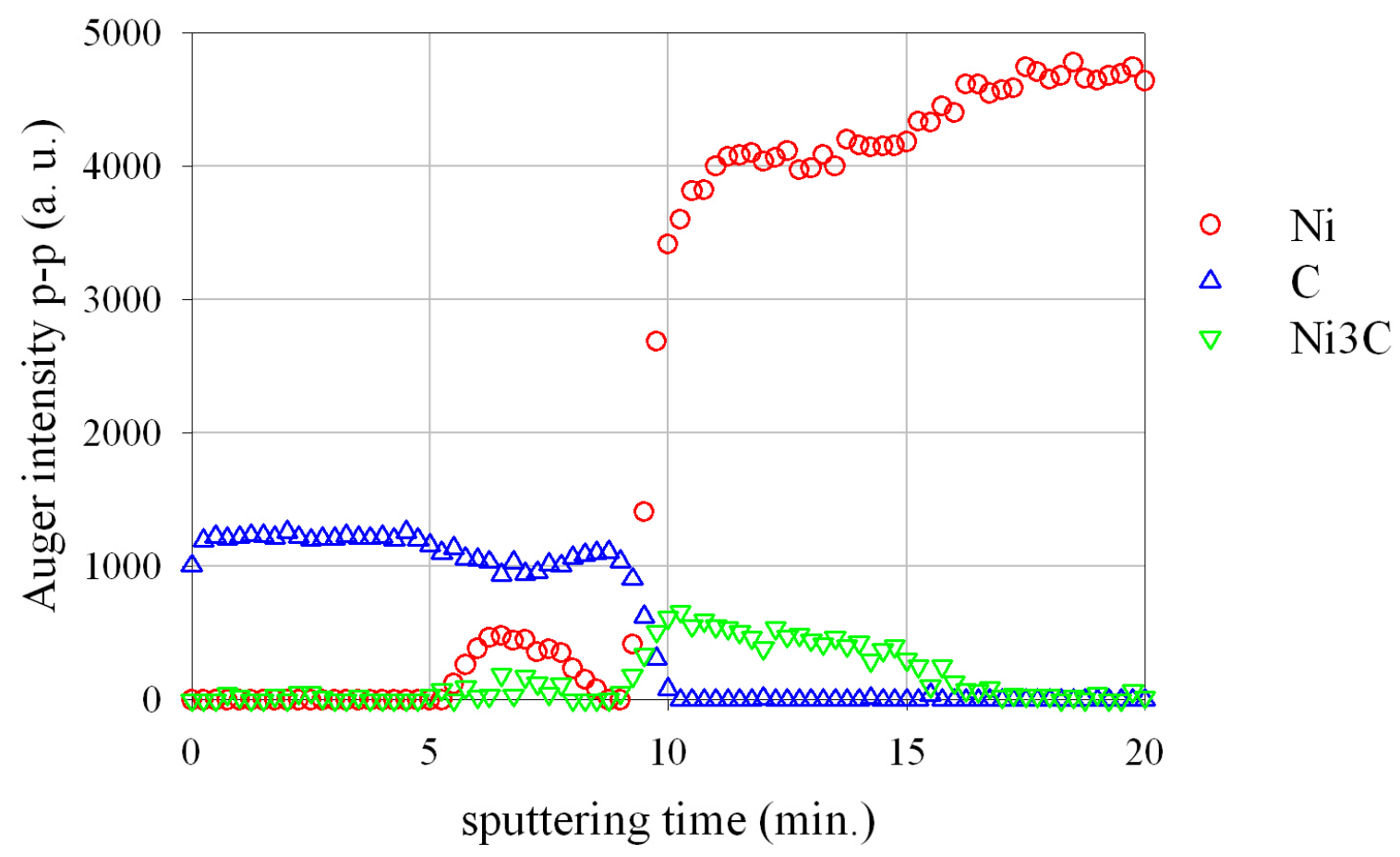

Figure $3 \mathrm{~b}$. The beginning part of the profile shown in figure $3 \mathrm{a}$. 


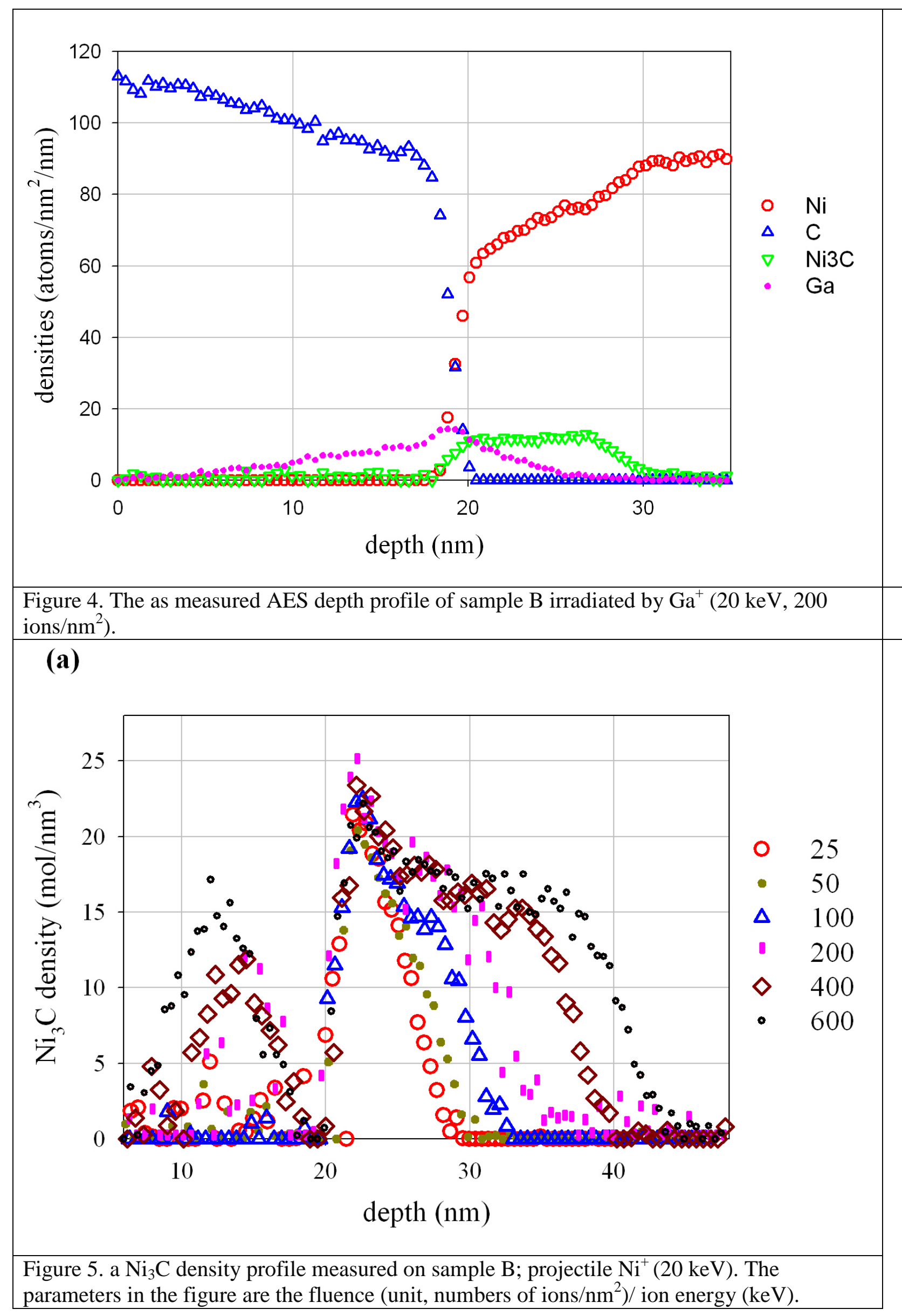



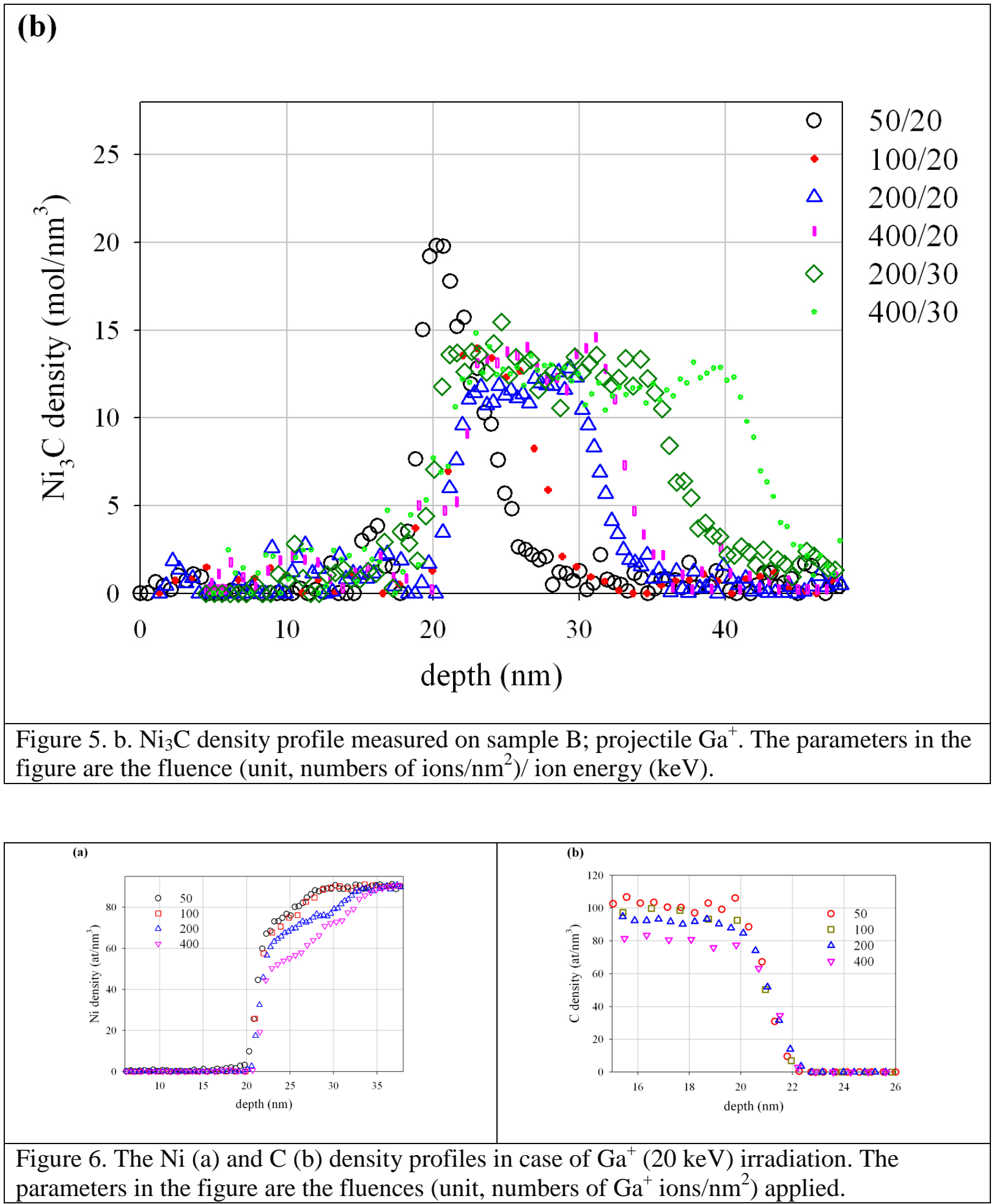


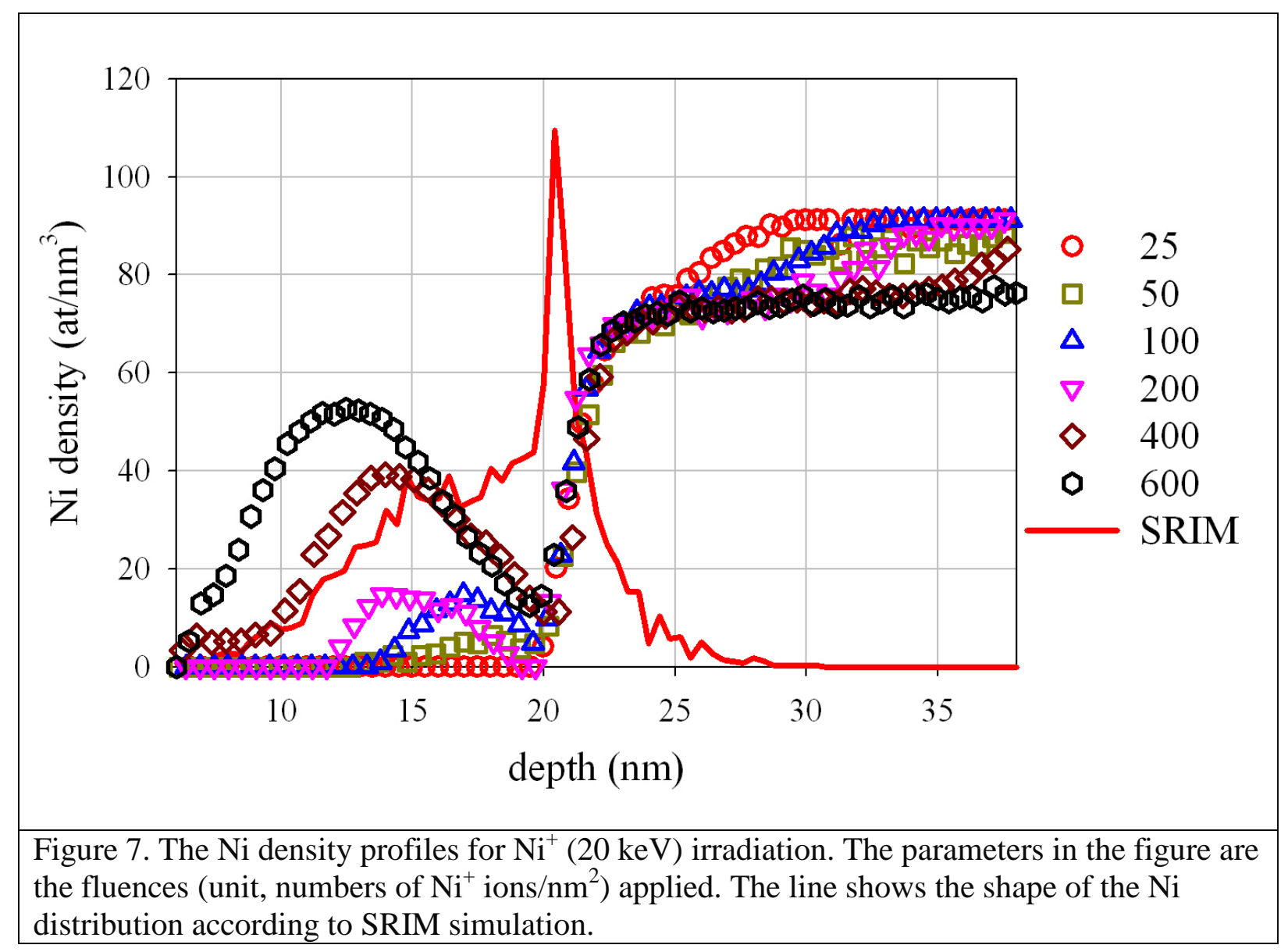




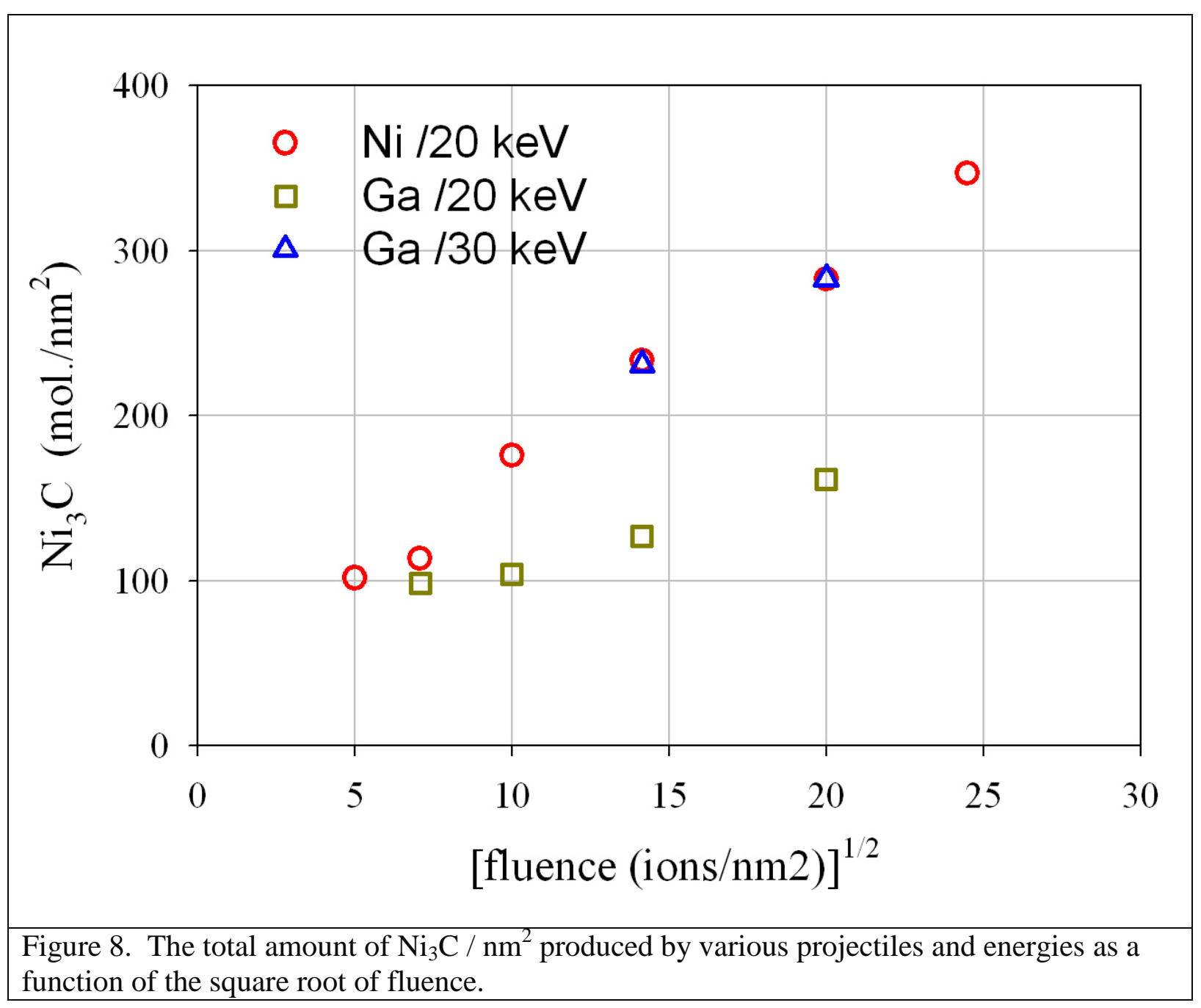




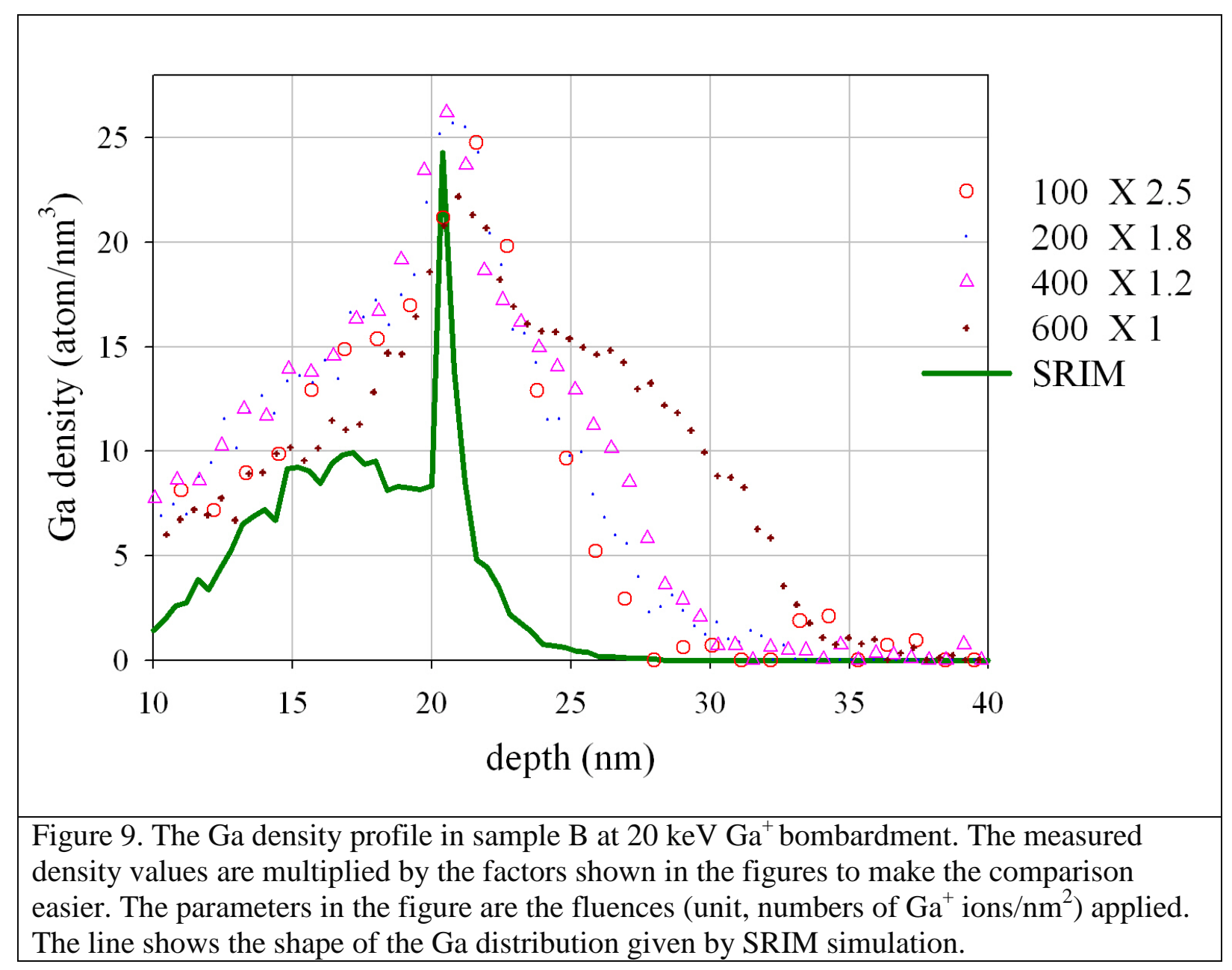




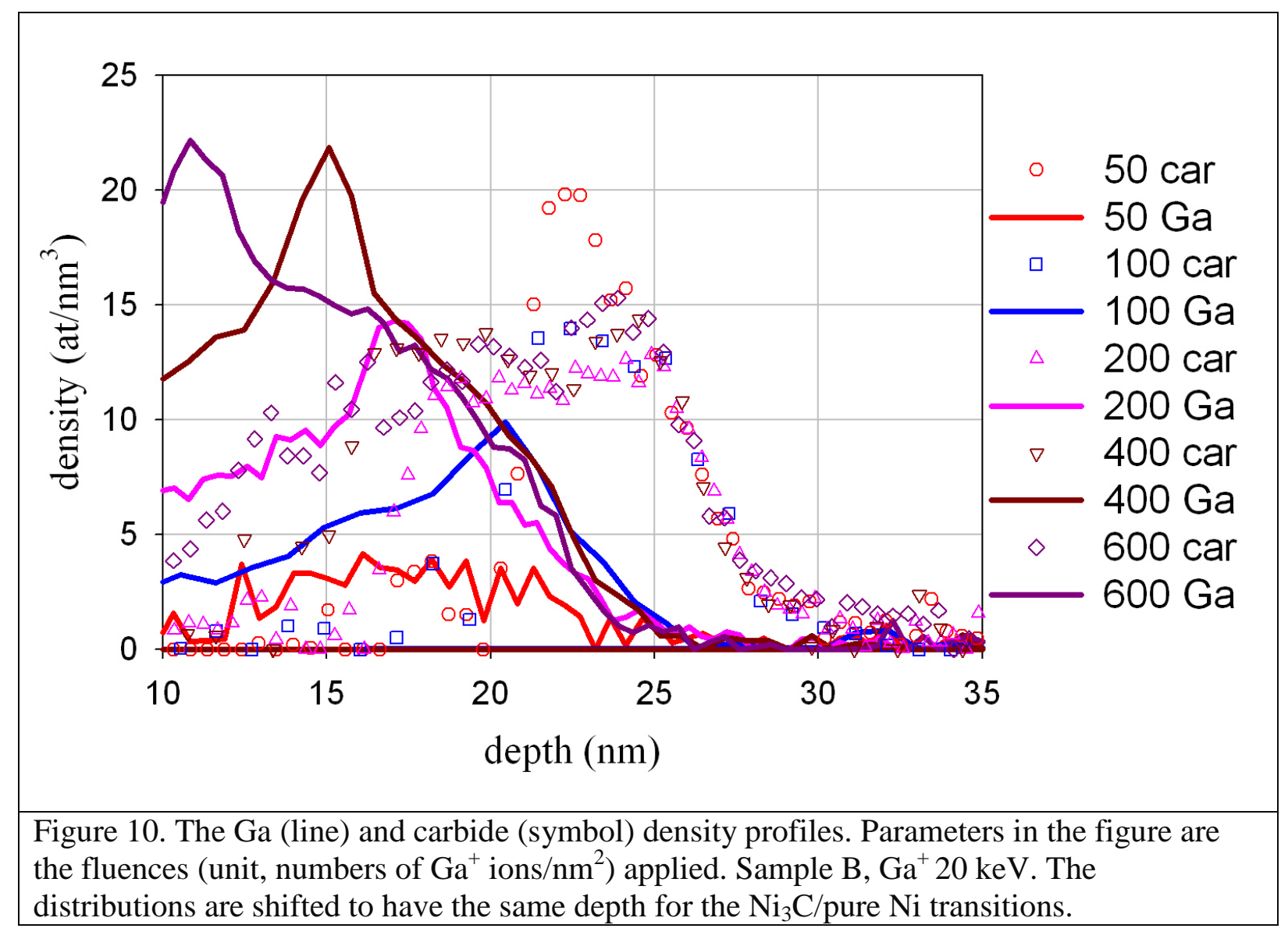

